\title{
Potential of Auxin in Inducing Spike Branching Trait in Black Pepper
}

\author{
Smitha Bhasi ${ }^{1}$, Swapna Alex ${ }^{1 *}$, K.B. Soni ${ }^{2}$ and Roy Stephen ${ }^{2}$ \\ ${ }^{1}$ Department of Plant Biotechnology, ${ }^{2}$ Department of Plant Physiology, College of Agriculture, \\ Vellayani-695 522, Kerala, India \\ *Corresponding author
}

\section{A B S T R A C T}

\section{Keywords \\ Black pepper, Spike branching trait, Indole-3- acetic acid (IAA), HPLC. \\ Article Info \\ Accepted: \\ 04 June 2017 \\ Available Online: \\ 10 August 2017}

Black pepper, the 'King of Spices' has high value in the international market. Natural varieties of Piper nigrum (black pepper) usually have non-branched spikes. However, a natural selection of black pepper viz. 'Pepper Thekken', shows inflorescence branching character i.e., about 20-30 branches per spike which is a trait of high economic value that is directly linked to the yield potential of this valuable spice crop. Auxin polar transport is reported to be one of the regulatory factors for branching architecture in many plants. Hence, in the present study, we tried to analyse the role of auxin in inducing branching trait in 'Thekken' through quantification of Indol acetic acid content in immature spikes using HPLC and comparing it with that of non-branching varieties like 'Karimunda' and "Panniyur1 ". The study revealed that the IAA content in the spikes of branching variety 'Thekken' was significantly low, that is about $1 / 4^{\text {th }}$ and $1 / 3^{\text {rd }}$ of 'Panniyur' and 'Karimunda' respectively.

\section{Introduction}

Black pepper, referred as 'King of spices' is a major export oriented spice crop of India. Normally, black pepper species have nonbranched spikes.

A pepper type viz., 'Thekken' a selection of Piper nigrum, made by a farmer in Idukki, Kerala exhibits profuse branching character with more than 30 well developed branches bearing about 300 berries altogether as shown in figure 1 which is a trait of high economic value that is directly linked to the yield potential.

The yield of berries from spikes of black pepper 'Thekken' is reported to be about four times that of the highest yielding varieties, Panniyur-1, Panniyur-3 Panniyur-5 and local varieties like 'Karimunda' (ICAR, 2010; Subba et al., 2014; Vimarsha et al., 2014).

Flowering is a highly regulated process (Hsing, 2011) and is influenced by multiple factors including environment and developmental signals.

Inflorescence architecture observed in nature is found to be highly diverse and observed in many plants (Brown et al., 2006).

Growth regulators such as auxins, cytokinins and carotenoid derivatives are reported to 
regulate the branching architecture through interfering with the signal transduction pathway of flowering (Gireesha et al., 2012; Shani et al., 2006; Kyozuka, 2007).

Among these growth hormones, auxin is one of the most important hormone in which has diverse role in plant growth and development (Taiz and Zeiger, 2002). Among the natural auxins available in plants, Indole-3-acetic acid (IAA) is the most abundant form of auxin. In plants, auxin is transported mostly via polar transport i.e., Polar Auxin Transport (PAT) which controls multiple developmental processes including shaping of inflorescence/ inflorescence branching (Muller and Layser, 2011; Yue et al., 2015).

The present study was taken up to analyse the difference in the auxin content viz., In dole Acetic Acid (IAA) between the branched and non-branched spiked varieties of black pepper, and to correlate its possible role in inflorescence branching by altered polar auxin transport rate.

\section{Materials and Methods}

\section{Plant Samples}

The black pepper varieties viz., 'Thekken' (branched) and non-branched ('Panniyur' and 'Karimunda') were raised and maintained.

\section{Morphological characterisation}

Morphological characterisation and comparison of the spikes of branched ('Thekken') and non-branched varieties ('Panniyur 1' and 'Karimunda') were carried out as per IPGRI descriptors.

\section{Quantification of IAA}

IAA was quantified by High Performance Liquid Chromatography (HPLC), using reverse phase $\mathrm{C} 18$ column which is the most frequently used column material in HPLC for IAA quantification.

\section{Sample collection}

Immature spike samples which were about 30 days after floral bud initiation were collected from branched variety 'Thekken' and nonbranched variety 'Panniyurl' and 'Karimunda' and stored in $-80^{\circ} \mathrm{C}$.

\section{Extraction of sample}

Extraction was carried out as per the standardised protocol (Kim et al., 2006). One gram immature spike of branched and nonbranched varieties stored in $-80^{\circ} \mathrm{C}$ was weighed. The three samples were then extracted separately with $100 \%$ methanol $(2.5$ $\mathrm{ml} / \mathrm{g}$.f.w) in mortar and pestle. Indol 3 propionic acid (IPA) was added as internal standard @ 10nmol/g.f.w to each extract. The extracts were then cleared by centrifugation @ $16,000 \mathrm{~g}$ for $10 \mathrm{~min}$ at $4^{\circ} \mathrm{C}$. The resulting supernatant from each extract was transferred to fresh tubes and further concentrated in a sand bath until the volume decreased to less than one-tenth of the initial.

\section{Serial partitioning}

Serial partitioning was carried out using ethyl acetate. Before partitioning, one volume of pure water was added to each extract in order to increase the polarity of the sample. $1 \mathrm{M}$ $\mathrm{KOH}$ was added to this and the $\mathrm{pH}$ was adjusted higher than 9 to keep IAA and IPA ionized. The extract was then partitioned against $100 \%$ ethyl acetate and centrifuged @ $16,000 \mathrm{~g}$ for 2 min to separate the aqueous and organic phases. The lower aqueous phase was transferred to a new tube. Concentrated acetic acid was added in order to reduce the $\mathrm{pH}$ of the solution below 3 so that IAA and IPA are conserved in protonated forms. This 
acidic sample was partitioned against $100 \%$ ethyl acetate and cleared by centrifugation. The upper organic phase was recovered and completely dried in a speed vaccum and then dissolved in $30 \mu \mathrm{l}$ of $100 \%$ methanol.

\section{HPLC}

Plant extracts dissolved in $100 \%$ methanol and the standard (IPA) were resolved on a reversed phase C18 column with an HPLC system. IAA and IPA were separated in the presence of $0.3 \%$ acetic acid using solvent gradient program. Thus the IAA content was analysed on a reversed phase HPLC column under a methanol gradient program in the presence of $0.3 \%$ acetic acid. The elution profile was traced by a dual monitoring system with a fluorescence detector. The chromatogram was analyzed with software, Empower2.

\section{Results and Discussion}

\section{IAA quantification}

The study shows that the IAA content in the spikes of branching variety 'Thekken' showed significantly very low value of about $1 / 4^{\text {th }}$ and $1 / 3^{\text {rd }}$ of 'Panniyur' and 'Karimunda' respectively. The result indicates the potential of the hormone auxin in regulating branching trait of spikes in black pepper. The chromogram generated for IAA content in branched variety 'Thekken' and non-branched variety 'Panniyur 1' and 'Karimunda' is given below as figures 2, 3 and 4 respectively and the IAA content quantified is given below as table 1 .

Several research reports reveal that inflorescence architecture/ branching is regulated by polar auxin transport, for example in the case of maize. In maize it is reported that the auxin content and its polar transport is regulated by PIN efflux carrier proteins maize (Forestan and Varotto, 2012; Forestan et al., 2015; Yue et al., 2015). In Arabidopsis thaliana, mutations observed in PIN proteins diminish polar auxin transport in inflorescence axes and affects the branching architecture (Galweiler et al., 1998).

The significantly very low content of the hormone in branched spikes may be due to the altered polar auxin transport which might be due to the altered expression of PIN efflux carrier proteins and this study results necessitates real time expression analysis study of pin efflux carrier proteins in the branched and non-branched spikes of black pepper in future.

Table.1 Quantification of IAA content in the immature spikes of branched and Non-branched varieties of black pepper

\begin{tabular}{|l|c|l|}
\hline variety & $\begin{array}{l}\text { Quantity of } \\
\text { IAA in } \\
\text { nmol/g.f.w }\end{array}$ & $\begin{array}{l}\text { Quantity of IAA in } \\
\text { ppb }\end{array}$ \\
\hline Thekken & 140 & 25 \\
\hline Karimunda & 337 & 60 \\
\hline Panniyur & 534 & 95 \\
\hline
\end{tabular}


Table.2 Morphological characterisation of the spikes of branched and Non-branched variety of black pepper

\begin{tabular}{|l|c|c|c|}
\hline Characteristics & \multicolumn{3}{|c|}{ Average value } \\
\hline & Branched variety & Non-branched variety \\
\hline & Thekken & Panniyur-1 & Karimunda \\
\hline Spike yield per plant & 100 & 60 & 20 \\
\hline Branches per spike & 60 & nil & nil \\
\hline Spike length(cm) & 18 & 17 & 7.5 \\
\hline Berries per spikelet & 8 & nil & nil \\
\hline Berries per spike & $\mathbf{4 8 0}$ & $\mathbf{7 6}$ & $\mathbf{3 6}$ \\
\hline 1000 berry weight(g) & 100 & 181 & \\
\hline Drying percentage & $40 \%$ & $90 \%$ & \\
\hline Berry size(mm) & 7 & 9 & \\
\hline
\end{tabular}

Fig.1 Branched variety of black pepper' 'Thekken' and non-branched variety
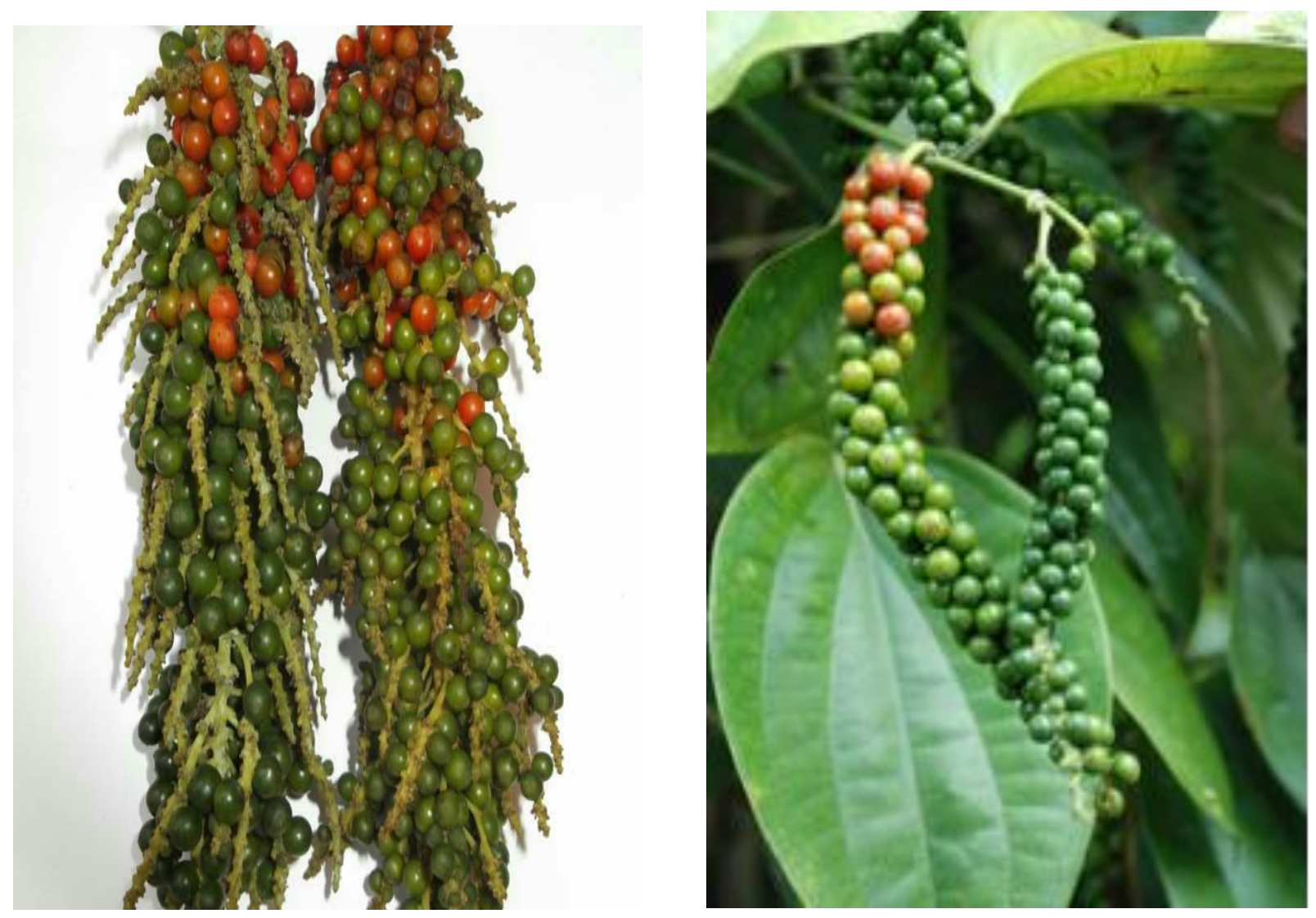
Fig.2 Chromogram for IAA content in 'Panniyur'

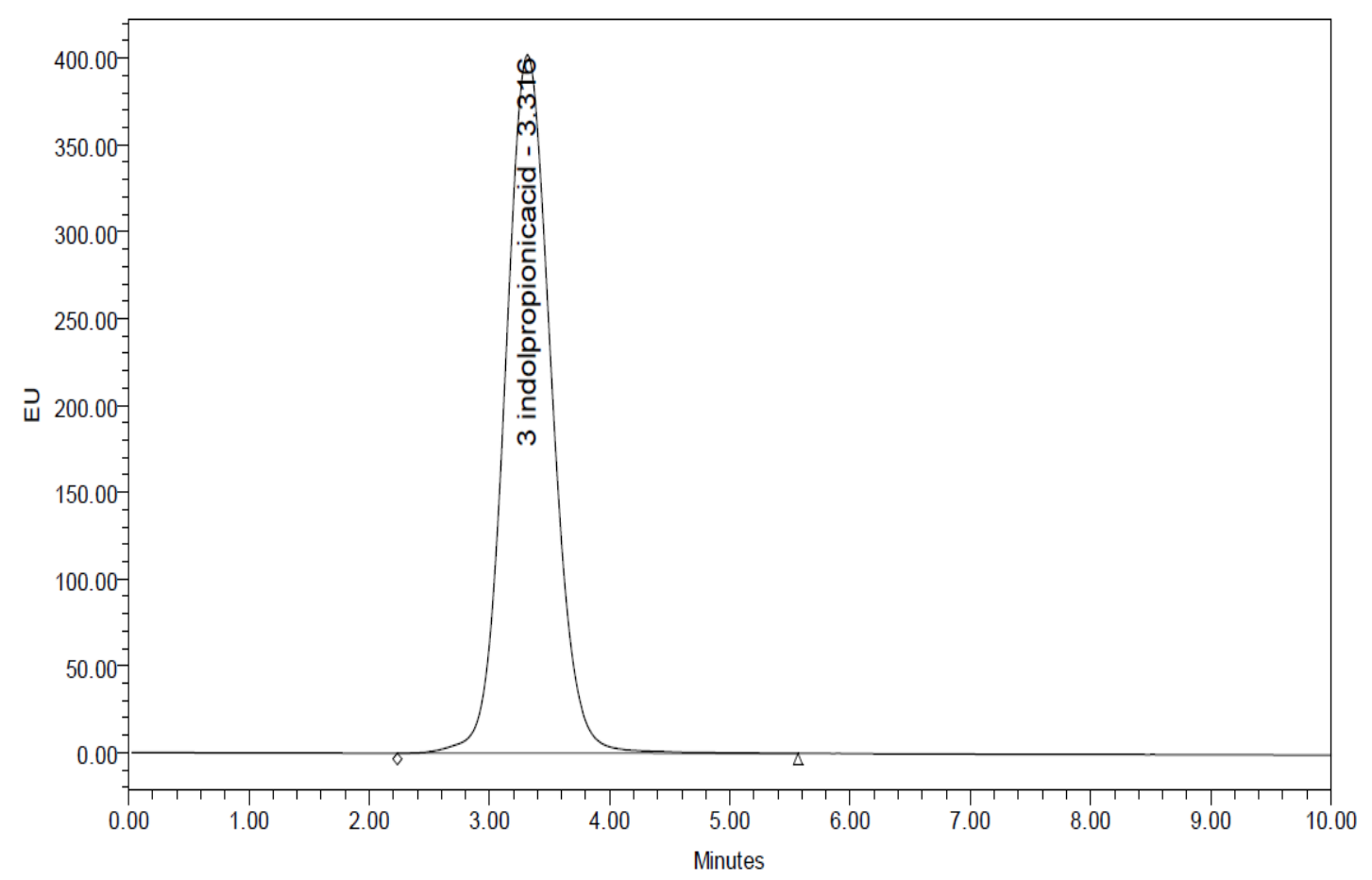

Fig.3 Chromogram for IAA content in 'Karimunda'

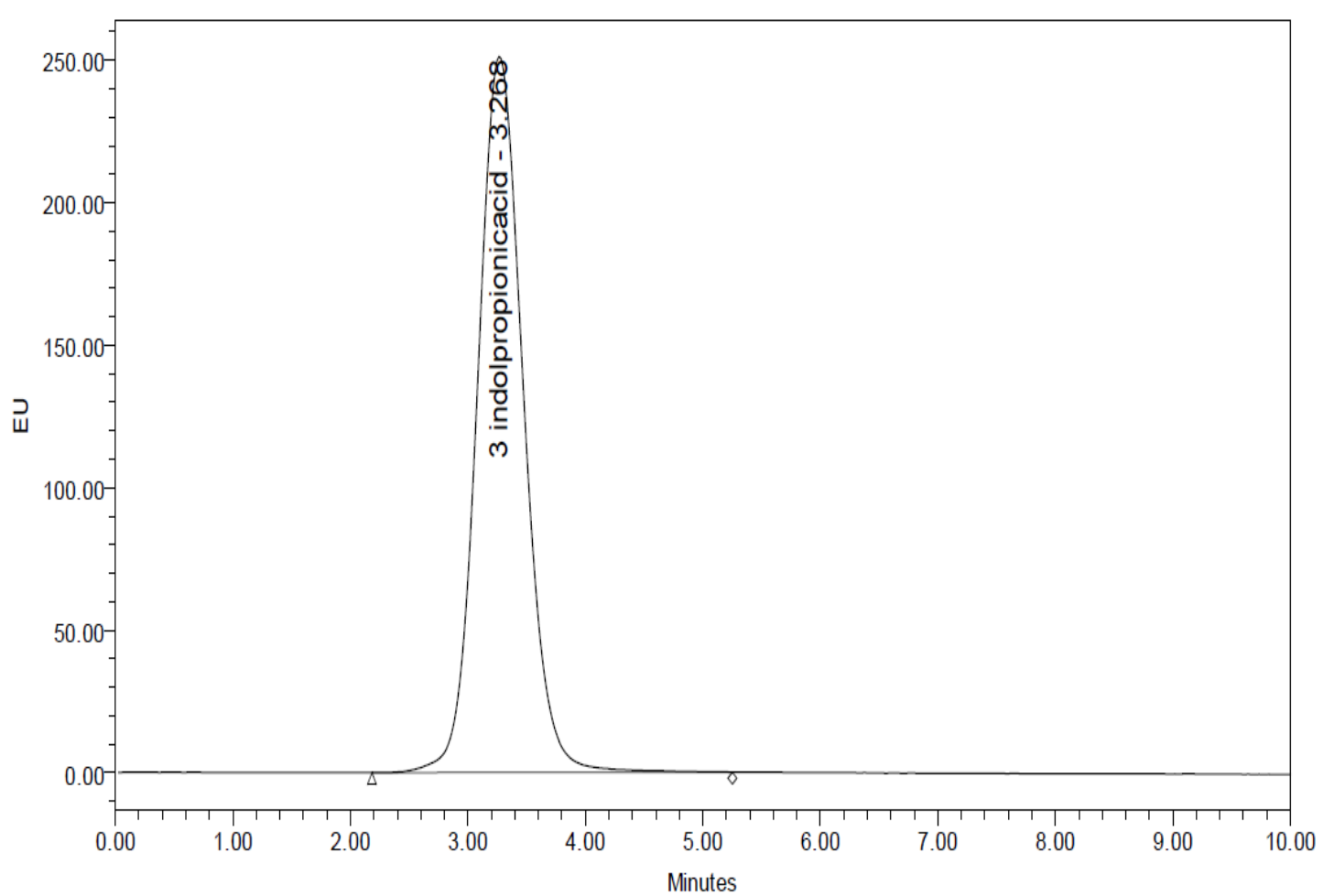


Fig.4 Chromogram for IAA content in 'Thekken'

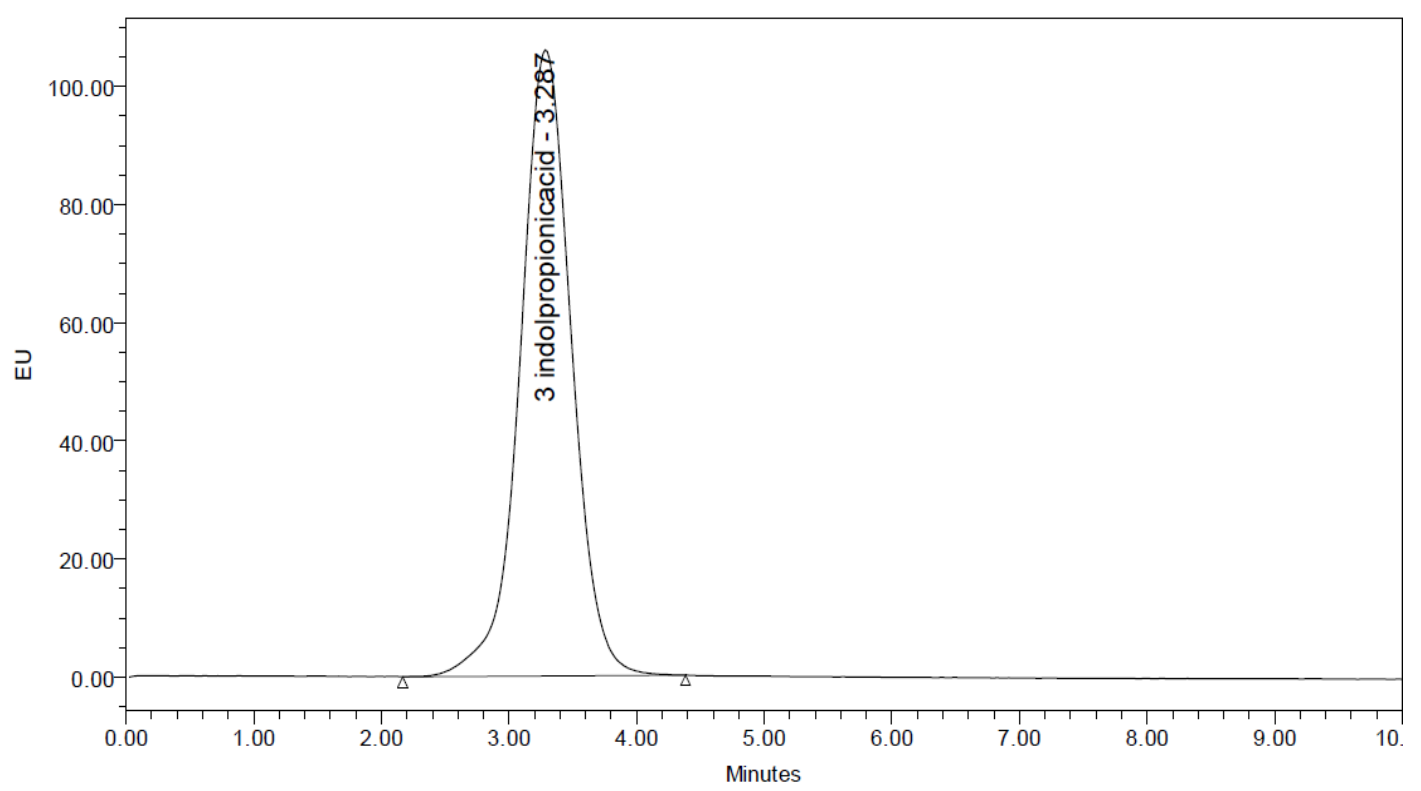

\section{HPLC analysis}

In the present study HPLC was used for quantification, since HPLC was reported as one of the best methods with high resolution and sensitivity for separating IAA. Also it is less costly when compared to GC-MS method. Among the various auxins produced in plants, IAA was quantified in the present study as it is reported to be the most abundant form of natural auxin in many crop plants. In this study, IPA was used as internal standard, since it was reported as ideal standards in HPLC (Forestan and Varotto, 2012) and also in GC-MS (Mezzetti, 2004) due to its high similarity to IAA and IPA is absent in plants.

\section{Morphological characterisation}

Morphological characterisation of the spikes of the branched and non-branched varieties of black pepper done as per IPGRI descriptors is given as table 2 . The result shows that the average number of berries per spike is 480 for branched variety 'Thekken' as against 76 for non-branched variety 'Panniyur-1' and 36 for 'Karimunda', which indicates that spike branching trait is directly related to yield attribute of a variety.

In conclusion, Auxin plays essential roles in many developmental processes in plants including gametogenesis, embryogenesis, seedling growth, vascular patterning, and flower development. The significant difference in the auxin content in the branched variety of black pepper 'Thekken' compared to the non-branched varieties of black pepper suggests a possible role of auxin in inducing branching trait in spikes of black pepper. The result of this study has wide practical utilisation in crops where branched inflorescence is the trait of commercial interest.

\section{Acknowledgement}

Financial assistance from Kerala State Council for Science, Technology and Environment, Government of Kerala, India for the project 'Molecular characterisation of spike branching trait in black pepper (Piper nigrum L.)' is gratefully acknowledged. 


\section{References}

Brown, P.J., Klien, P.E., Bortiri, E., Acharya, C.B., Rooney, W.L., and Kresovich, S. 2006. Inheritance of inflorescence architecture in sorghum. Theoretical and Applied Genetics. 113, 931-942.

Forestan, C. and Varotto, S. 2012. The role of PIN auxin efflux carriers in polar auxin transport and accumulation and their effect on shaping maize development. Molecular Plant. 5, 787-798.

Forestan, C., Farinati, S., and Varotto, S. 2015. The maize PIN gene family of auxin transporters. Frontiers in Plant Science. 3, 16-19.

Galweiler, L., Guan, C. H., Muller, A., Wisman, E., Mendgen, K., Yephremov, A., and Palme, K. 1998. Regulation of polar auxin transport by PINI in Arabidopsis vascular tissue. Science. 282, 2226-2230.

Girisha, R.,

Shirol, A.M., Kulkarni, B.S., Reddy, B.S. and Anupa, T. 2012. Studies on effect of different plant growth regulators on growth, flowering and quality of daisy (Aster amellus L.) cv. Dwarf Pink. International Journal of Agriculture Environment and Biotechnology. 5, 127131.

Hsing, C. Y. 2011. Flowering Research in Taiwan. Plant and Cell Physiology. 52, 1455-1458.

ICAR [Indian Council of Agriculture Research]. 2010. Farm innovators: Pepper 'Thekken'-black pepper variety. ICAR, New Delhi, p6.

Kim, Y. J., Oh, Y. J. and Park, W. J. 2006. HPLC-based quantification of Indole-3acetic acid in the primary root tip of maize. Journal of Nano and Biotech, 3,
40-45.

Kyozuka, J. 2007. Control of shoot and root meristem function by cytokinin. Current Opinion in Plant Biology. 10, 442-446.

Mezzetti B., Landi L., Pandolfini T. \& Spena A. 2004. The defH9-iaaM auxinsynthesizing gene increases plant fecundity and fruit production in strawberry and raspberry.BMC Biotechnology, 4, 4.

Muller, D. and Leyser, O. 2011. Auxin, cytokinin and the control of shoot branching. 2011. Annals of Botany. 107, 1203-1212.

Shani, E., Yanai, O., and Ori, N. 2006. The role of hormones in shoot apical meristem function. Current Opinion in Plant Biology. 9, 484-489.

Subba, A., Alex, S., Soni, K. B., Deepa, N.S.N., and Reghunath, B. R. 2014. Isolation of genomic DNA from mature leaves and spikes of black pepper (Piper nigrum L.). Journal of Plant Science and Research. 30, 21-25.

Taiz, L. and Zeiger, E. 2002. Plant Physiology, 3rd Ed, Sinauer, Sunderland.

Vimarsha, H. S., Sowjanya, M. S., Rajmohan, K., Soni K. B., and Alex, S. 2014. Attfl-1 gene homolog in spike branching black pepper type (Piper nigrum L.) and local variety Karimunda. Journal of Medicinal Plants Studies. 2, 1-4.

Yue, R., Tie, S., Sun, T., Zhang, L., Yang, Y., Qi, J., Yan, S., Han, X., Wang, H. and Shen, C. 2015. Genome wide identification and expression profiling analysis of ZmPIN, ZmLAX, ZmPILS and $Z m A B C B$ auxin transporter gene families in maize (Zea mays L.) under various abiotic stresses. PLOS ONE. 10, e0118751.

\section{How to cite this article:}

Smitha Bhasi, Swapna Alex, K.B. Soni and Roy Stephen. 2017. Potential of Auxin in Inducing Spike Branching Trait in Black Pepper. Int.J.Curr.Microbiol.App.Sci. 6(8): 372-378. doi: https://doi.org/10.20546/ijcmas.2017.608.050 